\title{
Applying Blockchain Technology in the Sphere of Payments and Financial Services
}

\author{
V. Nikiforova \\ Department of Economics and Finance \\ Financial University under the \\ Government of the Russian Federation \\ (Moscow), St. Petersburg Branch \\ St. Petersburg, Russia \\ A. Kovalenko \\ Department of Economics and Finance \\ Financial University under the \\ Government of the Russian Federation \\ (Moscow), St. Petersburg Branch \\ St. Petersburg, Russia
}

\author{
Y. Putikhin \\ Department of Economics and Finance \\ Financial University under the \\ Government of the Russian Federation \\ (Moscow), St. Petersburg Branch \\ St. Petersburg, Russia \\ M. Kreyer \\ Department of Social Sciences \\ Financial University under the \\ Government of the Russian Federation \\ (Moscow), St. Petersburg Branch \\ St. Petersburg, Russia
}

\author{
A. Nikiforov \\ Department of Economics and Finance \\ Financial University under the \\ Government of the Russian Federation \\ (Moscow), St. Petersburg Branch \\ St. Petersburg, Russia
}

\begin{abstract}
The paper is dedicated to comparative analysis of the result of using cryptocurrency based on blockchain technology in Russia and abroad. Different countries have different approaches to recognizing the cryptocurrency as a legal tender at the state and corporate levels. Thus, Japan has legalized cryptocurrencies and developed a regulatory and legal framework to introduce them in the economy. The USA has recognized the bitcoin as one of the official financial tools, but has not recognized it as a currency. In the UK bitcoins are considered private funds. In China cryptocurrencies are prohibited for government-owned companies and banks, but allowed for individuals. Europe recognizes bitcoins as a security, whereas Russia recognizes the status of cryptocurrencies as a digital commodity or asset. At the same time the diversity of approaches is complemented by the relevant legal regulation of blockchain technology. The paper discusses various problems related to blockchain technology applied not only as a basis of cryptocurrencies, but for a variety of uses in business, ITsystems and interaction between people. Economic and legal capabilities are revealed to use blockchain technology in the Russian Federation in the sphere of payments and financial services.
\end{abstract}

Keywords- blockchain technology, cryptocurrency, legal regulation, digital economy, economic and legal risks

\section{INTRODUCTION}

The world financial crisis of 2008 acted as a catalyst for the invention of blockchain, a system of decentralized data exchange, and the formation of a distributed secured ledger. Initially a part of the bitcoin algorithm, blockchain technology started to develop rapidly, bringing forward new digital currencies (Ripple, Ethereum, DASH, and more) and smart contracts. The attitude of government institutions and banks towards such cryptocurrencies varies. They recognize the progressive-ness of blockchain technology and fear that this technology could, on the one hand, lead to tax evasion, while on the other hand, to cashing out shadow funds and financing terrorism. In our opinion, a consensus has yet to be reached in the scientific community regarding the use of cryptocurrencies based on blockchain technology. The VI International Legal Forum, which took place in Saint Petersburg in 2017, gave special attention to the legal relations which arise in a digital environment and to the need for applying legal instruments in communication technologies. [1]

Under these conditions, it is especially of interest to carry out scientific debates and theoretical developments on the issue of creating a legal framework and using cryptocurrencies at the national level, as well as of creating a system for their government regulation. [2, 3, 4] The brief experience of a number of countries who have officially allowed the exchange and trade of cryptocurrencies (Singapore, Switzerland, and others), as well as of countries which recognize bitcoin as a method of payment (Japan, South Korea), and countries who ban the use of cryptocurrencies by legal entities, but allow their use by individuals (China), and so on, needs to be understood. It is quite clear that bitcoin technology can act as a base not only for cryptocurrencies but also for a number of business purposes, in IT systems, and for cooperation among people. Therefore, a balance needs to be struck between the traditional values and the new technical possibilities which blockchain technology provides in the area of payment transactions and financial services.

\section{BlOCKCHAIN TECHNOLOGY IN PAYMENTS AND FINANCIAL SERVICES}

The evolution of money from a commodity item to an electronic one has allowed for an understanding of the essential nature of money as a carrier of economic price information, a carrier which can appear in material or nonmaterial form. New information technologies in the field of payment and accounting are now becoming an important tool in the competition between large and small banks and between banks and other financial institutions. Remote banking, electronic receipts, electronic money wiring, and so on, have become a method of payment, based on transferring electromagnetically stored information. [5] Technically speaking, electronic payments can be carried out without the involvement of banks; they are transforming the payment system, turning it into a polycentric one. A certain period of time was needed for members of society to become used to these transactions, to increase their trust in the electronic 
money issuers and systems, and for this money to be recognized as legal tender at the national level.

Globalization and the development of digital technology are creating the prerequisites necessary to form a qualitatively new information environment capable of real-time money transfers and accounting on a global scale, as well as one capable of influencing the events and actions that take place on the planet and of determining the vector development of a new "financial civilization". As is known, blockchain technology, as an innovation in the area of information services, can be spread on the mega and macroeconomic levels by creating a corresponding digital ecosystem and can also be applied in many different types of economic activity and in the divisions of big business through the creation of private blockchain networks. [6]

The need for shared data necessitates the use of a distributed data-base, which provides, along with storage, the ability to carry out data management functions in certain nodes of the network, as well as the exchange of data between them using query execution. It is especially worth noting here the significance of the software based on which information management technology is applied in the field of finance. $[7,8]$

The appearance of blockchain technology in accounting and payment has a significant impact on the whole architecture of emerging relations in the financial services market. [9] This technology, which is based on the decentralized storage of databases and the multi-level cryptographic coding system, ensures the reliable accounting of cash equivalents. Bitcoin, as a cryptocurrency for monetary payments, firstly becomes information about its usefulness for transaction participants and society, information created by its proprietor; secondly, information, which is certified by the blockchain technology system as a public institution; thirdly, information, used by participants to measure their merits to other participants and the society.

In our opinion, the widespread introduction of blockchain technology into the traditional banking system, where the majority of ac-counting and payments are performed, is not very likely or effective due to a number of circumstances. First of all, it is due to the function of money in the banking system, which is based not on exchange, but instead on its nature of credit. This makes the transition to transactions based on universal exchange products more difficult. Secondly, it is due to the fragmented standardization of the banking system, which has yet to take on a global character. Third of all, it is related to the fact that the activities of the traditional banking system are based on support from the government, guarantees of deposit insurance, reversibility of operations, authentication of documents, and so forth, which is not offered by blockchain technology. Finally, smart contracts, as a software for legal transaction agreements, do not fit into existing banking regulation.

Along with this, it seems premature to consider cryptocurrency money just yet. There needs to be an accumulation and summary of the experience in countries where cryptocurrencies have been completely legalized (Japan and others). One problem that remains is the use of cryptocurrencies as a means of providing economic growth that satisfies domestic investment demands instead of as a speculative financial tool. There are ongoing heated debates about recognizing cryptocurrencies as property and creating the appropriate regulation for it. [10] A more pragmatic approach may be defining cryptocurrencies as material property instead of fiat money or securities.

At the same time, it is worth noting that the modern banking system in Russia experiences serious problems with interbank settlements during periods of crisis and needs to adopt blockchain technology. This will ensure information transparency regarding money transfers performed between banks, allowing the Central Bank, as the mega-regulator, to track all interbank and other money transfers in the banking sphere, while commercial banks will only track the money transfers of their clients, and the clients will only track their own payments. In 2016, more than 10 of the largest Russian banks, along with Qiwi and the Bank of Russia, were involved in the development of a technological platform based on the Ethereum code (with their own genesis block). The consortium "Fintech" was established to create blockchain technology prototypes and to develop a software complex, which would provide the storage and exchange of financial information by applying distributed ledger technology. [11] Practice shows that blockchain technologies are profitable for dependable banks which hope to get away from intermediaries in the paperwork, optimize costs, and prevent the loss of clients. Certain prospects are opening up to banks by adopting this technology in factoring (trade financing), in payment of services provided using letters of credit (based on the application of smart contracts), bank reporting, receiving reports from their clients, and so on

New financial institutes based on blockchain can be expected to appear, along with the adoption of blockchain technology in both the banking area as well as other areas of financial services, where trans-action costs are high and a lot of time is spent on payment negotiation and settlement. More than anything, this concerns the organization of direct peer financing, crowdfunding, the processing and sharing of financial information in auditing and accounting, the handling of securities in custody accounts, the accounting and reaccounting of rights to securities, and also other specific businesses. Therefore, the standardization of blockchain should record the main economic factors of its commercialization.

The information support of scientific research in the Russian economy, including research on the priorities of innovative companies and methods of decision support in the IT market, can also rely on using distributed ledger technology $[12,13,14]$.

Nowadays, blockchain technology is being used to solve certain management problems in the formation of real estate registries (Leningrad Oblast). The Rosreestr (the Russian federal service for state registration) and oracles, which input external data, fix the contract in blockchain, while a smart contract is signed between the interest holder and the developer. This contract contains the amount of the developer's insurance premium and the amount of the interest holder's advance payment on the real estate project to the protection fund, as well as the completion date of construction. Each of the parties forms their own node. When the completion date arrives, the program code is sent to the oracles to receive information on the readiness of the property. The blockchain network either automatically transfers the money from the protective fund account to the interest-holder's 
account if the entry into service of the property has passed the deadlines, or it makes a payment to the developer's account if the construction is finished on time. However, in order to make money payments, the cryptocurrency needs to be tied to the ruble, which is accomplished using the blockchain token. In this way, the double sale of an apartment and the risk of financial fraud are avoided.

A discussion is currently taking place in Russia on whether legislative provisions for the legal regulation of blockchain technology need to be developed. Some experts believe that in order for this technology to be used in the area of cryptocurrency trade there needs to be a special law and legal status given to these currencies. On the other hand, according to a number of experts, there is no need to develop legislative provisions for regulating blockchain technology, seeing as the products created with this technology and which represent information systems are already regulated by existing laws in the country regarding information, information technology, and information security. Along with the legislative regulation, the development of an industry standard of blockchain technology is being proposed, which can have mandatory application in areas such as state defense orders, use of atomic energy, and use of other information containing government, bank, and business secrets, as well as personal data. For information of limited access, legal risks arise in connection to the application of blockchain technology in products that allow the open distribution of information. These risks are generally due to the inability to determine the person responsible for spreading the information: the miner, agreement manager, or another person involved in the transaction. [15]

Another important part of this discussion, in our opinion, is finding out whether or not products created using blockchain technology are legally valid. If we look at the Russian legal proceedings, then we see that hash codes, which represent records in the blockchain, electronic documents, electronic signatures (simple, reinforced unqualified, and qualified) are recognized as admissible for proving legal facts. As far as smart contracts on blockchain platforms that are used in other fields besides payments and financial services, it is necessary to first and foremost ensure their consistency with the current laws in order to solve the issue of legalizing such contracts. This is the direction American lawmakers are headed in. In particular, the condition of such recognition is included in bills that recognize the legality of blockchain technology and smart contracts in a number of US states (Florida, Arizona). This does not contradict already existing laws and regulations.

Considering all the various approaches to legalizing cryptocurrencies in different countries around the world, an interdepartmental group at the State Duma, jointly with the Russian Ministry of Finance and the Central Bank of Russia, have laid the basis in Russia for the current efforts to draft bills to determine the status of cryptocurrency mining, licensing the use of cryptocurrencies for legal entities, using cryptocurrency crowdfunding, taxing operations of cryptocurrency, and so on. [16] The creation of a regulated environment for digital business offers a solution to a number of accompanying issues related to countering the laundering of criminal money and financing terrorism, fighting internet fraud, etc. At the legislative level, the most reasonable options seem to be to place cryptocurrencies at the same level as either federal loan bonds (suggested by the Russian Ministry of Finance), or money surrogates (suggested by the Central Bank of Russia). Whereby, using cryptocurrencies as a financial asset will not become publicly available to individuals and will be offered only between members of the regulated exchange. Therefore, they envisage the creation of a closed regulated environment of cryptocurrency trade, which is not intended for accounting, but instead for exchanging to a national or international currency.

By viewing this as a transitional step in the process of legalizing the use of cryptocurrency based on blockchain technology, we believe that it is dictated by the social economic situation that has developed in the country, and yet, this step is aimed at creating the continued development of the digital economy in Russia. In our opinion, it would be expedient for Russia to create science parks or clusters, introducing a decentralized system for organizing the circulation of crypto assets. In this case, legal risks related to the use of crypto assets are localized and companies will be the ones to carry the main legal burden. This would primarily be the exchanges and technological firms that deal with the equipment, programs, and services necessary for connecting and sharing information.

\section{CONCLUSIONS}

The prospects of using blockchain technology in the area of payment and finances in Russia are largely relevant for the banking and insurance sectors and are significant for accessing information on money transfers between banks, the truth on reporting data, the authenticity and reliability of clients for potential users, as well as for mechanisms of assessing the solvency of clients, financing trade, settling claims, using open licenses, and more. Whereby, the need to establish new ways of using information obtained by applying the new technology and the features of the technological process in making payments and providing financial services at the legislative level is not excluded.

Among the remaining problems with using blockchain technology is the issue of guarding the rights of those who use products created with this technology, seeing as the system is not always able to automatically ensure the necessary protection of rights. An optimal solution to reducing the legal risks in the area of cryptocurrency application would be the creation of a closed cluster environment for operating digital business while taking into account the peculiarities of the social and economic condition of the Russian economy. At the same time, a number of problems relating to the prevention of financial fraud in the area of internet payments, countering the laundering of criminal money and financing terrorism using crypto assets are solved. Closed blockchains can be applied in situations where the information being exchanged contains government, bank, or business secrets.

Open blockchains can already be developed today in the field of processing and sharing financial information, in auditing and accounting, handling securities in custody accounts, accounting and re-accounting of rights to securities, in creating real estate registries, as well as in other specific businesses. In the future, a wide range of applications of open blockchains in the Russian economy will open up in the organization of direct peer financing, lending and insurance, and crowdfunding. In this case, ensuring information security and reducing legal risks is possible by using integrated mining 
technologies which allow the same equipment to be used and thereby increase the security of more than one blockchain.

Furthermore, using blockchain technology for making payments and providing financial services will allow for the elimination of un-justified mediation, reduced prices in banking, insurance, and other commercial businesses, which will meet the marks of modern technical and technological support, security, decentralization, and different levels of accessibility. It will provide a greater involvement of savings in financing investment projects that are based on advanced algorithms and process large data while assessing the risks in each specific case. Objective: to identify economic and legal models for the Russian Federation to transfer to digital economy so as to expand the capacities of blockchain technology in the payment system, bank sphere, activities of financial institutions, formation of real estate registers and other spheres of the economy.

\section{REFERENCES}

[1] Site of the Government of Russia. URL: http://goverment.ru/news/23074 (date of retrieval 10.03.2018). Soc. London, vol. A247, pp. 529-551, April 1955.

[2] Pryanikov M.M., Chugunov A.V. Blockchain as a communication basis for forming a digital economy: ad-vantages and problems//International journal of open information technologies. ISSN: 2307-8162. Vol.5, No. 6, 2017.

[3] Strembitskaya S.B., Babayan S.G. Cryptocurrency in the financial services sector: new opportunities using the ex-ample of blockchain// European scientific conference digest of articles from the international academic conference. General editor G. Y. Gulyaeva. — 2017. — PP. 146-148

[4] Bulgakov I.T. Legal issues of blockchain technology use// Law. 2016. No. 12. PP. 80-88.

[5] Kochergin D.A. Electronic money: textbook/D.A. Kochergin. - M.: Market DS; TsIPSiR. - 2011. - P. 39

[6] Swan M. Blockchain: Blueprint for a new economy: translated into Russian - M.: Publisher "Olimp-Biznes”, 2017. - 240 p.
[7] Efremov, A.A., Loginova, A.V., Mikeladze, B.D., Shirokova, S.V. The models and technologies for supporting deci-sion making in design of information-control complexes. 2017. Proceedings of 2017 20th IEEE International Conference on Soft Computing and Measurements, SCM 2017

[8] Iliashenko, O.Y., Shirokova, S.V. Application of data-base technology to improve the efficiency of inventory man-agement for small businesses. 2014. WSEAS Transactions on Business and Economics.

[9] Blockchain Technology Market (Type - Public blockchain, private blockchain, and consortium blockchain; Application - financial services and non-financial sector) — Global industry analysis, size, share, growth, trends, and forecast 2016-2024 // Market research reports, industry research firms, consulting services. [Electronic resource] URL: http://www.transparencymarketresearch.com/blockchain-technologymarket.html (date of retrieval: 10.03.2018)

[10] The banking sector hates bitcoin but wants to keep blockchain. URL:http://getcoin.today/bankovskiy-sektor-nenavidit-bitcoin/(date of retrieval: 10.03.2018)

[11] Crypto technologies are being transferred to roubles. The Bank of Russia is gathering a consortium// Kommersant №117 from 04.07.2016 P. 8 - URL: http//|www.Kommersant.ru/doc/3029539

[12] Volkova, V.N., Loginova, A.V., Shirokova, S.V., Kozlovskay, E.A. Information support of scientific research in Russia. 2016. Proceedings of the 19th International Confer-ence on Soft Computing and Measurements, SCM 2016

[13] Volkova, V.N., Loginova, A.V., Shirokova, S.V., Iakovleva, E.A.Models for the study of the priorities of innovative companies. 2016. Proceedings of the 19th International Conference on Soft Computing and Measurements, SCM 2016

[14] Izotov, A., Rostova, O., \& Dubgorn, A. (2018). The application of the real options method for the evaluation of high-rise construction projects. Paper presented at the E3S Web of Conferences, , 33 doi:10.1051/e3sconf/20183303008

[15] Savelyev A.I. Contract Law 2.0: "smart" contracts as the beginning of the end of classical contract law // Herald of Civil Law. 2016. No.3. Pp. $32-40$.

[16] Kornilov D.A., Zaytsev D.A., Kornilova Y.V. Modern forms of crowdfunding and crowd selling, market analytics ICO//ITportal, 2017. No. 3(15) URL: http:// itpor-tal.ru/science/economy/sovremennyeformy-kraudfandinga-i-k/. 